\title{
Article \\ Genetic Association of the Functional WDR4 Gene in Male Fertility
}

\author{
Yu-Jia Wang ${ }^{1,+}$, Eko Mugiyanto ${ }^{2,+}$, Yun-Ting Peng 1,3, ${ }^{\dagger}$, Wan-Chen Huang ${ }^{4}$, Wan-Hsuan Chou 1,5 \\ Chi-Chiu Lee ${ }^{4}$, Yu-Shiuan Wang ${ }^{2}$, Lalu Muhammad Irham 1,6, Dyah Aryani Perwitasari ${ }^{6}$, Ming-I Hsu ${ }^{7, *}$ \\ and Wei-Chiao Chang 1,3,5,8,*
}

1 Department of Clinical Pharmacy, School of Pharmacy, College of Pharmacy, Taipei Medical University, Taipei 11031, Taiwan; jia_925@hotmail.com (Y.-J.W.); 101353@w.tmu.edu.tw (Y.-T.P.); ocean.chou@tmu.edu.tw (W.-H.C.); lalu.irham@pharm.uad.ac.id (L.M.I.)

2 PhD Program in Clinical Drug Development of Chinese Herbal Medicine, College of Pharmacy, Taipei Medical University, Taipei 11031, Taiwan; giyan77@gmail.com (E.M.); yswang1004@gmail.com (Y.-S.W.)

3 Department of Pharmacy, Wan Fang Hospital, Taipei Medical University, Taipei 11696, Taiwan

4 Institute of Cellular and Organismic Biology, Academia Sinica, Taipei 115, Taiwan; wanchen.huang@gmail.com (W.-C.H.); ccjosephlee@gmail.com (C.-C.L.)

5 Master Program for Clinical Pharmacogenomics and Pharmacoproteomics, School of Pharmacy, Taipei Medical University, Taipei 11031, Taiwan

6 Faculty of Pharmacy, University of Ahmad Dahlan, Yogyakarta 55164, Indonesia; diahperwitasari2003@yahoo.com

7 Department of Obstetrics and Gynaecology, Wan Fang Hospital, Taipei Medical University, Taipei 11696, Taiwan

8 Integrative Research Center for Critical Care, Wan Fang Hospital, Taipei Medical University, Taipei 11696, Taiwan

Citation: Wang, Y.-J.; Mugiyanto, E.; Peng, Y.-T.; Huang, W.-C.; Chou, W.-H.; Lee, C.-C.; Wang, Y.-S.; Irham, L.M.; Perwitasari, D.A.; Hsu, M.-I.; et al. Genetic Association of the Functional WDR4 Gene in Male Fertility. J. Pers. Med. 2021, 11, 760. https://doi.org/10.3390/jpm11080760

Academic Editor: Sara M. Falzarano

Received: 18 May 2021

Accepted: 27 July 2021

Published: 30 July 2021

Publisher's Note: MDPI stays neutral with regard to jurisdictional claims in published maps and institutional affiliations.

Copyright: (c) 2021 by the authors. Licensee MDPI, Basel, Switzerland. This article is an open access article distributed under the terms and conditions of the Creative Commons Attribution (CC BY) license (https:// creativecommons.org/licenses/by/ $4.0 /)$.
* Correspondence: hsumingi@yahoo.com.tw (M.-I.H.); wcc@tmu.edu.tw (W.-C.C.)

+ These authors equally contributed to this work.

Abstract: Infertility is one of the important problems in the modern world. Male infertility is characterized by several clinical manifestations, including low sperm production (oligozoospermia), reduced sperm motility (asthenozoospermia), and abnormal sperm morphology (teratozoospermia). WDR4, known as Wuho, controls fertility in Drosophila. However, it is unclear whether WDR4 is associated with clinical manifestations of male fertility in human. Here, we attempted to determine the physiological functions of WDR4 gene. Two cohorts were applied to address this question. The first cohort was the general population from Taiwan Biobank. Genomic profiles from 68,948 individuals and 87 common physiological traits were applied for phenome-wide association studies (PheWAS). The second cohort comprised patients with male infertility from Wan Fang Hospital, Taipei Medical University. In total, 81 male participants were recruited for the genetic association study. Clinical records including gender, age, total testosterone, follicle-stimulating hormone (FSH), luteinizing hormone (LH), total sperm number, sperm motility, and sperm morphology were collected. In the first cohort, results from PheWAS exhibited no associations between WDR4 genetic variants and 87 common physiological traits. In the second cohort, a total of four tagging single-nucleotide polymorphisms (tSNPs) from WDR4 gene (rs2298666, rs465663, rs2248490, and rs3746939) were selected for genotyping. We found that SNP rs465663 solely associated with asthenozoospermia. Functional annotations through the GTEx portal revealed the correlation between TT or TC genotype and low expression of WDR4. Furthermore, we used mouse embryonic fibroblasts cells from mwdr4 heterozygous (+/-) mice for functional validation by western blotting. Indeed, low expression of WDR4 contributed to ROS-induced DNA fragmentation. In conclusion, our results suggest a critical role of WDR4 gene variant as well as protein expression in asthenozoospermia.

Keywords: WDR4; genetic variants; male fertility; sperm quality 


\section{Introduction}

Infertility is defined as a disease characterized by the inability of couples to conceive a pregnancy after 12 months of regular unprotected intercourse [1]. Infertility is a global health issue affecting $8 \sim 12 \%$ of couples worldwide, and male infertility factors are responsible for about $20 \sim 30 \%$ of infertility cases. Approximately $7 \%$ of the male population is affected by infertility [2]. Evaluating male infertility is mainly based on semen analyses. The most significant abnormalities of semen quality include a low sperm number (oligozoospermia), poor sperm motility (asthenozoospermia), and abnormal sperm morphology (teratozoospermia) [3,4]. Oxidative stress has been considered as a critical factor to infertility that possibly associated with the DNA fragmentation [5]. Moreover, the DNA fragmentation levels were reported to correlate with sperm motility [6].

Genetic variations are considered as one of the important factors in male infertility. For example, the azoospermia factor (AZF) region in the long arm of the $\mathrm{Y}$ chromosome contains three sub-regions referred to as AZFa, AZFb, and AZFc. Microdeletions in these sub-regions cause impaired sperm production [7]. In addition, HSFY, which is related to the heat-shock transcription factor (HSF) family, has a long open reading frame carrying an HSF-type DNA binding domain involved in azoospermia. Some point mutations in the testis-specific HSFY gene family, such as microdeletions, may be a cause of unexplained cases of idiopathic male infertility [1]. Furthermore, Ozdemir et al. evaluated the genetic variants of SRY and AZF in male infertility [8]. Moreover, three SNPs (rs4920566, rs11763979, and rs3741843) on taste receptor genes (TASR) are associated with male infertility [9]. Several genes were further identified to correlate with infertility-related azoospermia in humans, such as RNU7-6P, ZFP64 [10], SOX5, PLCH2 [11], and ART3 genes [12].

$\mathrm{Wu}$ et al. reported that the $w h$ gene (Wuho gene with WD40 repeats, also named WDR4 in homo sapiens) is important in Drosophila spermatogenesis [13]. However, the physiological functions as well as the clinical manifestation for genetic variations of WDR4 gene are still unclear. Here, two cohorts were applied to address this question. The first cohort was the general population from Taiwan Biobank used for phenome-wide association study (PheWAS). The association between WDR4 variants and 87 common traits was comprehensively screened. The second cohort was male participants recruited from Wan Fang Hospital. The effects of WDR4 variants on human male infertility (oligozoospermia, asthenozoospermia, teratozoospermia) were investigated.

\section{Materials and Methods}

\subsection{Participant Recruitment and Sample Collection}

Men aged $\geq 20$ years old were recruited from the infertility clinic of Wan Fang Hospital, Taipei Medical University between November 2013 and June 2015. Participants with a history of vasectomy or cancer were excluded from the study. Semen samples were collected from every participant by masturbation after $3 \sim 5$ days of sexual abstinence. These samples were kept at room temperature and delivered to the reproductive laboratory for semen analysis within $1 \mathrm{~h}$. Peripheral blood samples were collected for serum hormone analysis and genomic DNA extraction. The study protocol was approved by the Taipei Medical University-Joint Institutional Review Board (TMU-JIRB) (No: 201302040), and written informed consent was received from all participants.

\subsection{Semen Analysis}

Semen samples were examined after liquefaction. Semen analysis was conducted separately by two experienced technicians in the reproductive laboratory. Semen parameters including total sperm number, sperm motility, and sperm morphology were evaluated. The World Health Organization (WHO) 2010 recommendations for semen analysis were followed [14]. A semen sample $(10 \mu \mathrm{L})$ was first transferred to a MAKLER counting chamber (Irvine Scientific, Santa Ana, CA, USA) to measure total number of spermatozoa. Oligozoospermia was defined as a number of sperm $<39 \times 10^{6}$ spermatozoa. The motility of each spermatozoon was graded into three categories: progressive motility (PR), non- 
progressive motility (NP), and immotile spermatozoa. Asthenozoospermia was defined as PR $<32 \%$. For sperm morphological evaluation, each spermatozoon was classified into eight groups as follows: normal sperm (NS), amorphous head (AH), duplicated head (DH), large head ( $\mathrm{LH})$, small head (SH), normal head with other defect $(\mathrm{NH})$, tapering head $(\mathrm{TH})$, and other defect (OD). Teratozoospermia was defined as $<4 \%$ of morphologically normal spermatozoa. In addition, combined oligozoospermia was defined as participants with sperm number less than $39 \times 10^{6}$ spermatozoa and other defects (astheno- and/or teratozoospermia), a rationale also applied to two other sperm characteristics (combined asthenozoospermia and combined teratozoospermia).

\subsection{Genomic DNA Extraction}

Peripheral blood samples were first centrifuged at $3000 \mathrm{rpm}$ and $4{ }^{\circ} \mathrm{C}$ for $10 \mathrm{~min}$ to separate serum and blood cells. The buffy coat layer was extracted and washed with red blood cell (RBC) lysis buffer to isolate peripheral blood mononuclear cells (PBMCs). PBMCs were then lysed using a cell lysis buffer. Proteins were precipitated using a protein precipitation solution followed by $95 \%$ isopropanol and $80 \%$ alcohol to isolate total genomic DNA. Finally, the DNA purity and concentration were measured using NanoDrop (Thermo Fisher Scientific, Wilmington, DE, USA).

\subsection{Genotyping of SNPs in the WDR4 Gene}

Tagging (t)SNPs with a minimum allele frequency (MAF) of $>10 \%$ in a Beijing Han Chinese (CHB) population were selected through UCSC (http:/ / genome.ucsc.edu) and HapMap vers. 2010-08_phase II + III (http:/ / hapmap.ncbi.nlm.hig.gov/). Haploview 4.2 was applied for tSNP selection. A total of four SNPs of the WDR4 gene were selected and genotyped (Figure 1). Characteristics of these SNPs are shown in Table S1. Genotyping was performed using the TaqMan Allelic Discrimination Assay (Applied Biosystems, Foster City, CA, USA). A polymerase chain reaction (PCR) was carried out with an ABI StepOnePlus Thermal Cycler (Applied Biosystems). The fluorescence from different probes was measured and analyzed by System SDS software vers. 2.2.2 (Applied Biosystems).

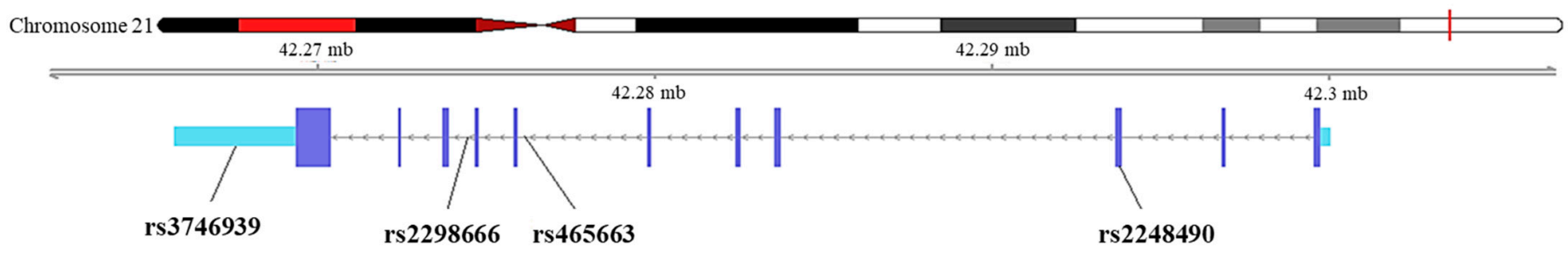

Figure 1. Graphic view of the genotyped WDR4 gene.

\subsection{Functional Annotation Data Query}

Tissue-specific cis-expression quantitative trait loci (cis-eQTL) were queried from the GTEx Portal (http:/ / www.gtexportal.org/home/) to evaluate the effects of the SNPs on gene expressions in different human tissues. Data were obtained from the Genotype-Tissue Expression (GTEx) Portal on 4 May 2020.

\subsection{Phenome-Wide Association Study (PheWAS)}

A phenome-wide association study (PheWAS) was conducted to screen the association between WDR4 genetic variation and common traits. Imputed Axiom Genome-Wide TWB 2.0 Array data from 68,948 individuals were obtained from the Taiwan Biobank. The data were subjected to quality control based on a variant call rate $(>98 \%)$, sex check, sample call rate $\left(>98 \%\right.$ ), Hardy-Weinberg equilibrium (HWE; $p>10^{-6}$ ), heterozygosity (within the mean \pm 3 standard deviations (SDs)), and identical by descent (IBD) check $(<0.1875)$. After quality control and extracting common variants (with minor allele frequencies of $>0.05), 3,982,815$ variants and 59,448 individuals remained. Furthermore, 105 variants of 
the WDR4 gene were extracted to conduct the PheWAS with 87 phenotypes using Plink v1.9 (www.cog-genomics.org/plink/1.9/) [15,16].

\subsection{Cell Culture}

The mouse embryonic fibroblasts (MEF) used in this study were purchased from $\mathrm{mWh}$ heterozygous mice (+/ -) [17] and maintained in DMEM (GIBCO, 11995) contained with $10 \%$ FBS, $1 \%$ Pen/Strep (GIBCO, 15140122). The $3 \times 10^{5}$ cells were seeded in $6 \mathrm{~cm}$ culture dish for $24 \mathrm{~h}$ before treated with $\mathrm{H}_{2} \mathrm{O}_{2}$.

\subsection{Western Blotting}

To detect the reactive oxygen species (ROS)-caused DNA damage, cells were treated with $100 \mu \mathrm{M} \mathrm{H}_{2} \mathrm{O}_{2}$ for $24 \mathrm{~h}$. Cells were then lysed, and the total proteins were analyzed by $10 \%$ SDS-polyacrylamide gel. After running the gel, proteins were transferred to a PVDF membrane and blocked with 5\% non-fat dry milk for $1 \mathrm{~h}$ at RT. Membranes were then washed with PBST (PBS contained with $0.1 \%$ Tween 20) and incubated with primary antibodies in 1:1000 dilutions overnight at $4{ }^{\circ} \mathrm{C}$; second antibodies were incubated in 1:5000 dilutions for $1 \mathrm{~h}$ at RT. The peptides LKKKRQRSPFPGSPEQTK were synthesized to detect mouse $\mathrm{Wdr} 4$ protein (mWdr4). The antibody was purified by affinity chromatography with peptide antigens before use [17]. The protein band intensities were detected by an ECL-plus detection system (GE Healthcare, RPN2235).

\subsection{Statistical Analysis}

For the PheWAS, plink v1.9 was used for analysis (www.cog-genomics.org/plink/ $1.9 /$ ) $[15,16]$. Furthermore, the simpleM method was used for variants (18 independent variants after correction), and Pearson's correlation was used for phenotypes (76 independent phenotypes after correction with $\mathrm{r}^{2}>0.7$ ) to adjust the number of independent tests for multiple testing correction in PheWAS [18]. In this study, tests with $p<3.65 \times 10^{-5}$ $(0.05 / 18 \times 76)$ were regarded as significant for phenome-wide associations. For the WDR4 genetic association study with male infertility, R 3.2.0 (http:/ /www.r-project.org) was used for the statistical analysis. HWE of SNPs was evaluated using a Chi-squared test. Magnitudes of associations between SNPs and semen quality parameters were examined through a linear regression analysis under a recessive model. Age, total testosterone, follicle-stimulating hormone (FSH), and luteinizing hormone ( $\mathrm{LH}$ ) were included as covariates in the regression model. $p<0.05$ was considered statistically significant.

\section{Results}

\subsection{PheWAS for WDR4 Variants in A Taiwanese Population}

To further explore the roles of WDR4 in human traits, a PheWAS was conducted to investigate associations between WDR4 variants and common traits in a Taiwanese population. The associations between 105 variants of WDR4 gene and 87 phenotypes were tested through the PheWAS. A variety of associations between the WDR4 genetic variants and the common phenotypes were identified at the significance level of $p<0.05$. However, none of them remained significant after multiple testing correction (Figure 2). 


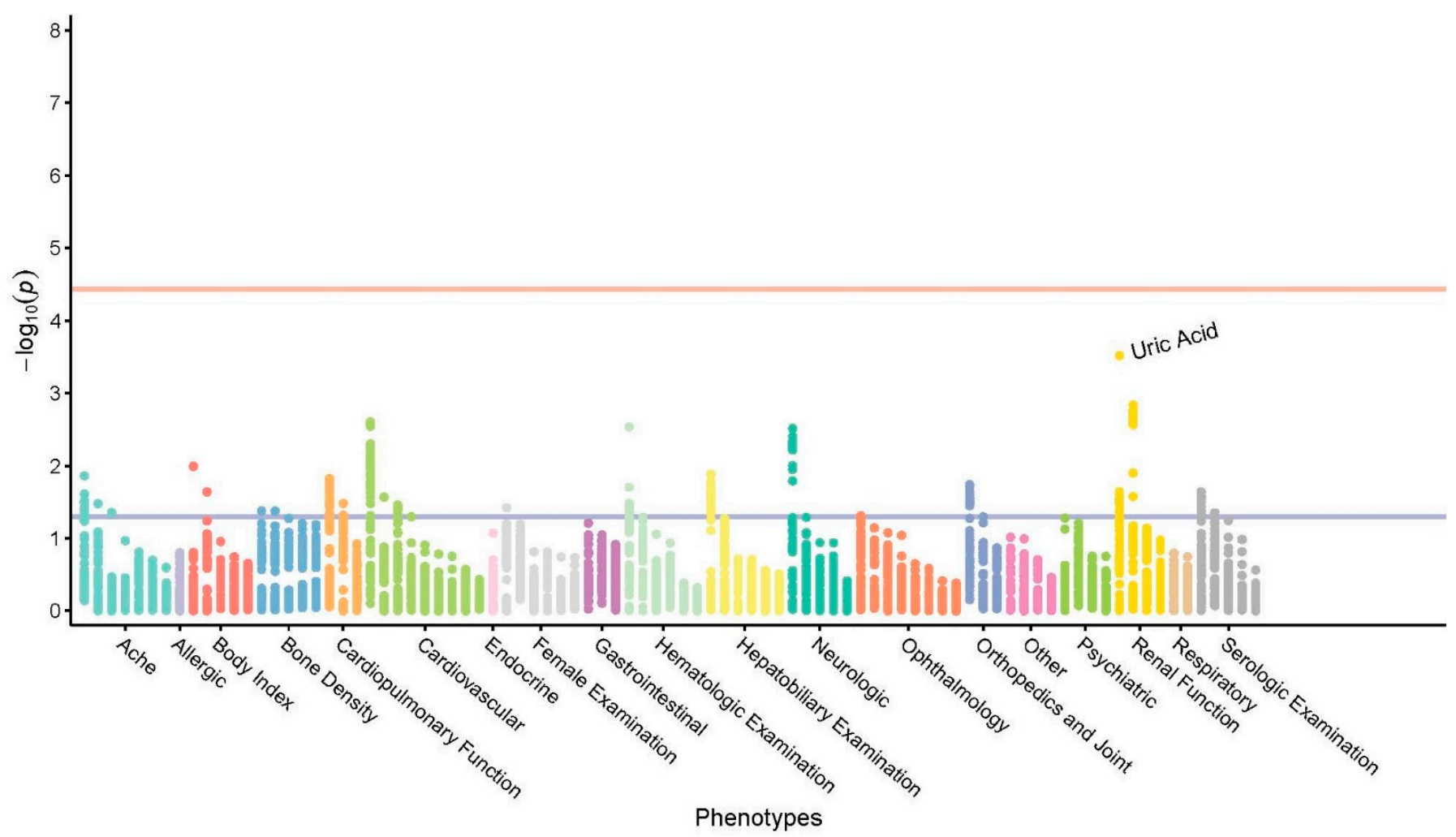

Figure 2. Phenome-wide scan for associations with WDR4 variants. The blue line represents $p=0.05$, and the red line represents the significance level for phenome-wide associations after multiple testing corrections $\left(p=3.65 \times 10^{-5}\right)$.

\subsection{Participant Characteristics}

Eighty-one males were recruited from the infertility clinic. Participants were aged 28 51 years, with a mean age of 36 years. Men with oligozoospermia, asthenozoospermia, and teratozoospermia accounted for $15 \%, 27 \%$, and $7 \%$, respectively. Their clinical characteristics are summarized in Table 1. Furthermore, correlation coefficient of age, serum hormones, and semen parameters were shown by Spearman's rank correlation. In agreement with the previous study, our data demonstrated morphology decline with age, whereas follicle-stimulating hormone (FSH) levels rose (Figure S1) [19]. 
Table 1. Characteristics of the 81 male participants.

\begin{tabular}{|c|c|c|}
\hline Characteristic & Participants & Normal Range \\
\hline Age (years) ${ }^{a}$ & $36.21 \pm 4.58$ & \\
\hline Range (years) & 27 51 & \\
\hline \multicolumn{3}{|c|}{ Semen analysis, no. $(\%)$} \\
\hline \multicolumn{3}{|c|}{ Oligozoospermia (total sperm number $<39 \times 10^{6}$ ) } \\
\hline Oligozoospermia & $12(15)$ & \\
\hline Isolated & 9 & \\
\hline Combined & 3 & \\
\hline Non-oligozoospermia & $69(85)$ & \\
\hline \multicolumn{3}{|c|}{ Asthenozoospermia $(\mathrm{PR}<32 \%)$} \\
\hline Asthenozoospermia & $22(27)$ & \\
\hline Isolated & 10 & \\
\hline Combined & 12 & \\
\hline Non-asthenozoospermia & $59(73)$ & \\
\hline \multicolumn{3}{|c|}{ Teratozoospermia (sperm with normal morphology $<4 \%$ ) } \\
\hline Teratozoospermia & $6(7)$ & \\
\hline Isolated & 0 & \\
\hline Combined & 6 & \\
\hline Non-teratozoospermia & $75(93)$ & \\
\hline \multicolumn{3}{|l|}{ Serum hormone analysis ${ }^{a}$} \\
\hline Total testosterone (ng/mL) & $4.87 \pm 1.59$ & $2.51 \sim 10.60$ \\
\hline FSH $(\mathrm{mIU} / \mathrm{mL})$ & $5.42 \pm 4.24$ & $1 \sim 14$ \\
\hline $\mathrm{LH}(\mathrm{mIU} / \mathrm{mL})$ & $2.40 \pm 1.59$ & $1.5 \sim 9.2$ \\
\hline SHBG (nmol/L) & $28.88 \pm 14.82$ & $14.5 \sim 48.4$ \\
\hline Inhibin B (pg/mL) & $252.40 \pm 162.44$ & - \\
\hline $\mathrm{TSH}(\mu \mathrm{IU} / \mathrm{mL})$ & $1.63 \pm 0.82$ & $0.34 \sim 5.60$ \\
\hline T3 (ng/dL) & $112.20 \pm 18.06$ & $87 \sim 178$ \\
\hline $\mathrm{T} 4(\mu \mathrm{g} / \mathrm{dL})$ & $8.15 \pm 1.28$ & $6.09 \sim 12.23$ \\
\hline Free T4 (ng/dL) & $0.90 \pm 0.10$ & $0.61 \sim 1.12$ \\
\hline $\mathrm{AMH}(\mathrm{ng} / \mathrm{mL})$ & $12.51 \pm 7.84$ & - \\
\hline $\operatorname{Zinc}(\mu \mathrm{g} / \mathrm{L})$ & $1076.10 \pm 217.26$ & $800 \sim 1200$ \\
\hline
\end{tabular}

a Mean \pm standard deviation. PR, progressive motility; FSH, follicle-stimulating hormone; LH, luteinizing hormone; SHBG, sex hormone-binding globulin; TSH, thyroid-stimulating hormone; T3, triiodothyronine; T4, thyroxine; AMH, anti-müllerian hormone. — No optimal recommendation available for male.

\subsection{Associations between WDR4 Variants and Oligozoospermia}

The effects of four SNPs on total sperm number were first evaluated. There were no statistically significant differences in genotypic distributions between oligozoospermia cases and the non-oligozoospermia group (Table 2).

Table 2. Associations between genetic variants of the WDR4 gene and oligozoospermia.

\begin{tabular}{|c|c|c|c|c|c|c|}
\hline \multirow{2}{*}{ SNP } & \multirow{2}{*}{ Genotype } & \multicolumn{2}{|c|}{ Cases } & \multicolumn{2}{|c|}{ Non-Oligozoospermia } & \multirow{2}{*}{$\begin{array}{c}\text { Recessive Model } \\
p \text {-Value }\end{array}$} \\
\hline & & No. & $\%$ & No. & $\%$ & \\
\hline \multirow[t]{3}{*}{ rs2298666 } & GG & 10 & 83.3 & 48 & 70.6 & 0.665 \\
\hline & GA & 2 & 16.7 & 18 & 26.5 & \\
\hline & $\mathrm{AA}$ & 0 & 0 & 2 & 2.9 & \\
\hline \multirow[t]{3}{*}{ rs465663 } & $\mathrm{TT}$ & 9 & 75.0 & 33 & 49.3 & 0.157 \\
\hline & $\mathrm{TC}$ & 3 & 25.0 & 24 & 35.8 & \\
\hline & $\mathrm{CC}$ & 0 & 0 & 10 & 14.9 & \\
\hline \multirow[t]{3}{*}{ rs2248490 } & $\mathrm{CC}$ & 8 & 66.7 & 30 & 43.5 & 0.095 \\
\hline & CG & 4 & 33.3 & 29 & 42.0 & \\
\hline & GG & 0 & 0 & 10 & 14.5 & \\
\hline \multirow[t]{3}{*}{ rs3746939 } & $\mathrm{AA}$ & 8 & 66.7 & 37 & 53.6 & 0.165 \\
\hline & $\mathrm{AC}$ & 4 & 33.3 & 27 & 39.1 & \\
\hline & $\mathrm{CC}$ & 0 & 0 & 5 & 7.2 & \\
\hline
\end{tabular}

The $p$-value was adjusted for age, total testosterone, follicle-stimulating hormone, and luteinizing hormone. SNP single-nucleotide polymorphism. 


\subsection{Associations between WDR4 Variants and Asthenozoospermia}

Next, the effects of four SNPs on total sperm motility were analyzed. As shown in Table 3, the genotypic distribution of rs465663 differed between asthenozoospermia and non-asthenozoospermia groups. The proportions of TT and TC genotypes were higher in asthenozoospermia compared to non-asthenozoospermia $(p=0.025)$.

Table 3. Associations between genetic variants of the WDR4 gene and asthenozoospermia.

\begin{tabular}{ccccccc}
\hline \multirow{2}{*}{ SNP } & Genotype & \multicolumn{2}{c}{ Cases } & \multicolumn{2}{c}{ Non-Asthenozoospermia } & Recessive Model \\
\cline { 3 - 6 } & & No. & $\%$ & No. & $\%$ & -Value \\
\hline rs2298666 & GG & 17 & 81 & 41 & 69.5 & 0.399 \\
& GA & 4 & 19 & 16 & 27.1 & \\
rs465663 & AA & 0 & 0 & 2 & 3.4 & $0.025^{*}$ \\
& TT & 15 & 71.4 & 27 & 46.6 & \\
& TC & 6 & 28.6 & 21 & 36.2 & 0.677 \\
rs2248490 & CC & 0 & 0 & 10 & 17.2 & \\
& CC & 15 & 68.2 & 23 & 39 & \\
& CG & 5 & 22.7 & 28 & 47.5 & \\
& GG & 2 & 9.1 & 8 & 13.6 & \\
& AA & 15 & 68.2 & 30 & 50.8 & \\
& AC & 6 & 27.3 & 25 & 42.4 & \\
& CC & 1 & 4.5 & 4 & 6.8 & \\
\hline
\end{tabular}

The $p$-value was adjusted for age, total testosterone, follicle-stimulating hormone, and luteinizing hormone. $* p<0.05$. SNP, single-nucleotide polymorphism.

\subsection{Associations between WDR4 Variants and Teratozoospermia}

The effects of four SNPs on normal sperm morphology were also examined. As shown in Table 4, no statistically significant differences in genotypic distributions were observed between teratozoospermia cases and the non-teratozoospermia group.

Table 4. Associations between genetic variants of the WDR4 gene and teratozoospermia.

\begin{tabular}{|c|c|c|c|c|c|c|}
\hline \multirow{2}{*}{ SNP } & \multirow{2}{*}{ Genotype } & \multicolumn{2}{|c|}{ Cases } & \multicolumn{2}{|c|}{ Non-Teratozoospermia } & \multirow{2}{*}{$\begin{array}{c}\text { Recessive Model } \\
p \text {-Value }\end{array}$} \\
\hline & & No. & $\%$ & No. & $\%$ & \\
\hline \multirow[t]{3}{*}{ rs2298666 } & GG & 5 & 83.3 & 53 & 71.6 & 0.759 \\
\hline & GA & 1 & 16.7 & 19 & 25.7 & \\
\hline & AA & 0 & 0 & 2 & 2.7 & \\
\hline \multirow[t]{3}{*}{ rs465663 } & TT & 5 & 83.3 & 37 & 50.7 & 0.395 \\
\hline & $\mathrm{TC}$ & 1 & 16.7 & 26 & 35.6 & \\
\hline & $\mathrm{CC}$ & 0 & 0 & 10 & 13.7 & \\
\hline \multirow[t]{3}{*}{ rs2248490 } & $\mathrm{CC}$ & 5 & 83.3 & 33 & 44 & 0.154 \\
\hline & $\mathrm{CG}$ & 1 & 16.7 & 32 & 42.7 & \\
\hline & GG & 0 & 0 & 10 & 13.3 & \\
\hline \multirow[t]{3}{*}{ rs3746939 } & $\mathrm{AA}$ & 4 & 66.7 & 41 & 54.7 & 0.186 \\
\hline & $\mathrm{AC}$ & 2 & 33.3 & 29 & 38.7 & \\
\hline & $\mathrm{CC}$ & 0 & 0 & 5 & 6.7 & \\
\hline
\end{tabular}

The $p$-value was adjusted for age, total testosterone, follicle-stimulating hormone, and luteinizing hormone. SNP, single-nucleotide polymorphism.

\subsection{Functional Annotation from GTEx Portal for rs465663}

The profile of WDR4 gene expression in various tissues was determined by the GTEx portal database (Figure 3). In the genetic association analysis, rs465663, an intronic variant of WDR4, was associated with asthenozoospermia. To further elucidate the possible functions of rs465663, cis-eQTL results were retrieved from the GTEx portal. rs 465663 could affect the expression level of several genes in different tissue types. Subjects carrying the T allele showed a lower expression level of WDR4 in testes, whole blood, and esophageal mucosal tissue (Table S2). 


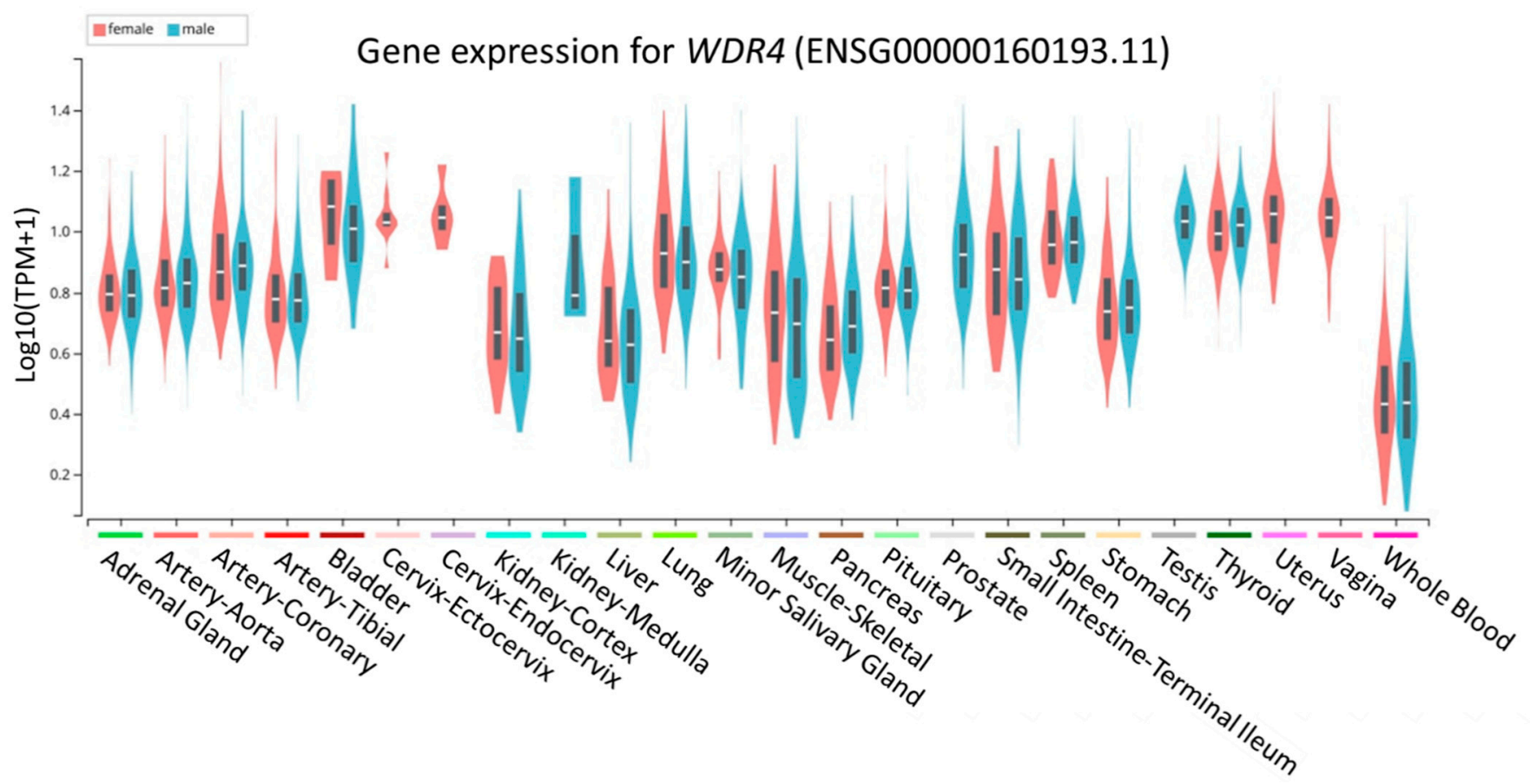

Figure 3. Profile of WDR4 gene expression in various tissues. Blue represents the male gender and red the female gender.

\subsection{Effects of WDR4 in DNA Fragmentation through $\gamma H 2 A X$ Expression}

Previous studies showed that the sperm DNA fragmentation level was increased by ROS stress and was correlated with sperm motility $[5,6]$. The higher expression level of $\gamma \mathrm{H} 2 \mathrm{AX}$ (biomarker of DNA fragmentation level) was revealed to correlate with male infertility [20]. To investigate the role of WDR4 in male infertility, the MEF (mouse embryonic fibroblasts) cells were isolated from mwdr4 heterozygous (+/-) mice, and the $\mathrm{H}_{2} \mathrm{O}_{2}$ was used to induce DNA fragmentation for mimicking oxidative stress. The mwdr4 and the $\gamma \mathrm{H} 2 \mathrm{AX}$ protein expression levels were confirmed with western blotting (Figure 4). The results showed that the $\mathrm{mWdr} 4$ protein expression level in the $\mathrm{mWdr} 4$ heterozygous MEF group was low. Importantly, the $\mathrm{H}_{2} \mathrm{O}_{2}$-induced $\gamma \mathrm{H} 2 \mathrm{AX}$ protein level was highly increased in the mwdr4 heterozygous MEF group compared to the wild type MEF group. These results highlighted an important role of WDR4 in male infertility.

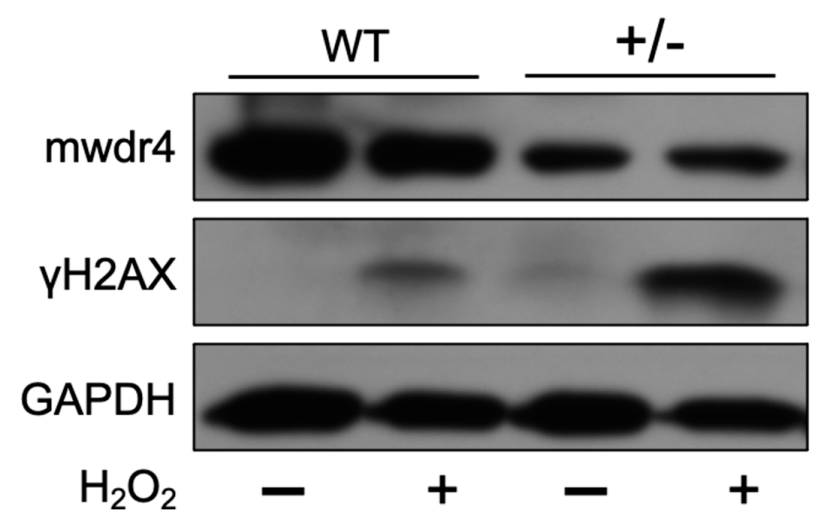

Figure 4. $\mathrm{H}_{2} \mathrm{O}_{2}$-induced $\gamma \mathrm{H} 2 \mathrm{AX}$ expression increased in wdr4 heterozygous (+/-) MEF cells. The MEFs cells were subcultured into $6 \mathrm{~cm}$ culture dish $24 \mathrm{~h}$ before being treated with $100 \mu \mathrm{M} \mathrm{H}_{2} \mathrm{O}_{2}$. The mwdr4, the $\gamma \mathrm{H} 2 \mathrm{AX}$, and the GAPDH protein expression levels were determined by western blot after $\mathrm{H}_{2} \mathrm{O}_{2}$ treatment for $24 \mathrm{~h}$. 


\section{Discussion}

Wuho is a member of the evolutionarily conserved WD repeat protein family that is expressed by the genes wuho in Drosophila, TRM82 in yeast, and WDR4 in humans [17]. The WDR4 domains usually contain four to eight repeating sequences, which are separated by approximately 40 amino acids. Each repeat consists of two sites, a poorly conserved site and a well-conserved site [21]. Wu at al. reported that the lack of WDR4 function is associated with dramatic germline-specific phenotypes by arresting the spermatogenesis at the spermatid elongating stage [13]. The study indicated that approximately $20 \%$ of the ovarioles in WDR4 mutant female have apparent defects in oogenesis with an over-proliferation of cystocytes. Additionally, WDR4 is associated with germline cell development through cytosolic tRNA modifications [22].

Male infertility is characterized (manifested) by low sperm production (oligozoospermia), reduced sperm motility (asthenozoospermia), and abnormal sperm morphology (teratozoospermia). In this study, we wanted to seek out whether any genetic variants associate with the clinical outcomes. Importantly, the analysis using continuous traits showed consistent results with dichotomous models (Tables S3-S5). Asthenozoospermia and oligozoospermia are the most common factors responsible for male infertility [23]. In line with this, our study indicated that asthenozoospermia comprised the most cases followed consecutively by oligozoospermia and teratozoospermia. Here, we identified variants of the WDR4 gene that related to male infertility. rs465663 significantly associated with the susceptibility to asthenozoospermia. The variation in rs465663 was located in the intronic region of chromosome 21, while proportions of the TT and the TC genotypes of rs465663 were higher than the CC genotype in cases with asthenozoospermia. Interestingly, the $C$ allele is the minor allele of rs465663. The distribution of the minor allele of rs465663 in current study was lower than those reported in other populations, including Asians, Europeans, and Americans (Table S1). Trends of infertility globally showed that two populations of Europeans, represented by Central and Eastern Europe (8 12\%), and Americans, represented by North America (4.5 6\%), were higher compared to Sub-Saharan Africans (2.5 4.8\%); unfortunately, those studies did not provide the percentage of Asians, possibly due to underreporting [24].

Our findings also emphasized that functional annotations through a bioinformatic approach using the GTEx portal revealed that subjects had lower expression of the TT genotype of WDR4 than the CC and the TC genotypes in several human tissues, including testes and whole blood. Meanwhile, the major allelic frequency of rs465663 of WDR4 had lower expression in testes. This result implied that rs465663 might influence expression of the WDR4 gene, especially in testes. Disease-related male infertility can be caused by testicular deficiencies and spermatogenesis [4]. This evidence provided additional clues that variations of the WDR4 gene may affect the testes, including their production of sperm (Figure 3). Furthermore, we noticed that ROS-induced DNA fragmentation level was significantly increased in the low WDR4 group (Figure 4). The results further support the possibility that lower expression of WDR4 in males resulted in infertility.

Several phenotypes are associated with WDR4 variants, such as rs370189685, which was correlated with the fasting plasma glucose level [25]. A study from Drosophila germ cells suggested that WDR4 is a regulator of Mei-p26, and it interacts with TRIM32 to control tissue homeostasis in other stem cell systems [26]. Other genes related to male infertility were identified to associate with azoospermia (e.g., SOHLH1 [27], SYCP3 [28], and TEX11 [29]). WDR4 gene with a missense mutation was reported to be related to primordial dwarfism through $\mathrm{m}^{7} \mathrm{G}_{46}$ methylation, which impaired transfer (t)RNAs [30]. Sperm carries thousands of different RNAs [31]. Interestingly, according to the REACTOME database (R-HSA-6782315) [32], variations in rs465663 of the WDR4 gene might involve in RNA metabolism and tRNA modifications in nuclei and cytosol. tRNAs play pivotal roles in protein synthetases. Mutations in tRNAs which modify enzymes are associated with human diseases, including cancer, type 2 diabetes (T2D), neurological disorders, and mitochondrion-linked disorders [33]. Furthermore, as reported by a previous study, 
tRNA modifications can affect proteostasis in humans [34]. A similar study supported that tRNA modifications in mice resulted in increased apoptosis in male germ cells and male infertility [35]. In addition, epigenomic assays are also essential for relating noncoding genetic variations to regulatory mechanisms underlying phenotypic changes, including genomic variations of the WDR4 gene. The Encyclopedia of DNA Elements (ENCODE) database revealed that rs465663 is located in an intronic region with known histone modifications [32]. Subsequent evidence revealed that an epigenomic histone modification was involved in male fertility [36]. Some genes, such as FAM50B and GNAS, were reported to involve in the quality of sperm in asthenozoospermia through histone modification-type methylation [37]. Taken together, previous studies provided comprehensive integration between the identified genetic variants and male infertility.

Our research is focusing on the genetic variants of WDR4 in male fertility s. However, some limitations still exist in this study. First, although the subject number $(68,948$ individuals) for PheWAS was good, no significant physiological traits were found. Regarding the second cohort (male participants) from the hospital, the small sample size limits the statistical power. Thus, larger sample sizes with different populations are necessary to confirm our findings. Second, as the candidate gene approach was performed, the influence of variants in other unexamined genes cannot be ruled out. Since the pathophysiology of infertility in humans is complexly regulated by many signaling pathways, using whole genome sequencing technology may yield further insights into the genomic variations in infertility.

\section{Conclusions}

This study offers important information related to genetic variants and expression level of the WDR4 which might affect infertility in the cases of asthenozoospermia. However, further functional studies and larger sample sizes are required to validate the variants.

Supplementary Materials: The following are available online at https:/ / www.mdpi.com/article/10 .3390/jpm11080760/s1, Figure S1: Spearman's rank correlation coefficient between age, serum hormones, and semen parameters, Table S1: Characteristics of tagging single-nucleotide polymorphisms (tSNPs) of the WDR4 gene, Table S2: Cis-expression quantitative trait loci (cis-eQTL) of rs465663, Table S3: Associations between genetic variants of the WDR4 gene and total sperm number, Table S4: Associations between genetic variants of the WDR4 gene and sperm progressive motility, Table S5: Associations between genetic variants of the WDR4 gene and sperm morphology.

Author Contributions: Conceptualization: Y.-J.W., Y.-T.P., W.-H.C., M.-I.H. and W.-C.C.; sample collection: Y.-J.W. and Y.-T.P.; data curation: Y.-J.W., Y.-T.P., M.-I.H. and W.-C.C.; formal analyses: Y.-J.W., Y.-T.P., W.-H.C., M.-I.H. and W.-C.C.; experimental preparation: C.-C.L., Y.-S.W., W.-H.C.; data interpretation and discussion: Y.-J.W., Y.-T.P., E.M., W.-C.H., W.-H.C., C.-C.L., Y.-S.W., L.M.I., D.A.P., M.-I.H. and W.-C.C.; writing review \& editing: Y.-J.W., Y.-T.P., E.M., W.-C.H., W.-H.C., C.-C.L., Y.-S.W., L.M.I., D.A.P., M.-I.H. and W.-C.C.; supervision: W.-C.H., D.A.P., M.-I.H. and W.-C.C. All authors have made significant contributions to this study. All authors have read and agreed to the published version of the manuscript.

Funding: This work was supported by grants from the Health and welfare surcharge of tobacco products grant (MOHW110-TDU-B-212-144014; MOHW110-TDU-B-212-144020), Ministry of Science and Technology, Taiwan (MOST109-2314-B-038-131 and MOST110-2628-B-038-020), and Taipei Medical University, Taiwan (12310-106079; Yusuke Nakamura Chair Professorship).

Institutional Review Board Statement: This study was approved by the Taipei Medical UniversityJoint Institutional Review Board (TMU-JIRB no: 201302040). Samples were collected from participants after they had provided written informed consent.

Informed Consent Statement: Informed consent was obtained from all subjects involved in the study.

Acknowledgments: The paper is in memory of academician, Tao-shih Hsieh, Academia Sinica, Taiwan. Thanks to his guidance and initiation of this project.

Conflicts of Interest: The authors declare no conflict of interest. 


\section{References}

1. Zegers-Hochschild, F.; Adamson, G.; de Mouzon, J.; Ishihara, O.; Mansour, R.; Nygren, K.; Sullivan, E.; Vanderpoel, S. International Committee for Monitoring Assisted Reproductive Technology (ICMART) and the World Health Organization (WHO) revised glossary of ART terminology, 2009. Fertil. Steril. 2009, 92, 1520-1524. [CrossRef]

2. Vander Borght, M.; Wyns, C. Fertility and infertility: Definition and epidemiology. Clin. Biochem. 2018, 62, 2-10. [CrossRef] [PubMed]

3. Esteves, S.C. Clinical relevance of routine semen analysis and controversies surrounding the 2010 World Health Organization criteria for semen examination. Int. Braz. J. Urol. 2014, 40, 433-453. [CrossRef] [PubMed]

4. Jungwirth, A.; Giwercman, A.; Tournaye, H.; Diemer, T.; Kopa, Z.; Dohle, G.; Krausz, C.G. European Association of Urology Guidelines on Male Infertility: The 2012 Update. Eur. Urol. 2012, 62, 324-332. [CrossRef] [PubMed]

5. Moustafa, M.H.; Sharma, R.; Thornton, J.; Mascha, E.; Abdel-Hafez, M.A.; Thomas, A.J.; Agarwal, A. Relationship between ROS production, apoptosis and DNA denaturation in spermatozoa from patients examined for infertility. Hum. Reprod. 2004, 19, 129-138. [CrossRef] [PubMed]

6. $\quad$ Elbashir, S.; Magdi, Y.; Rashed, A.; Ibrahim, M.A.; Edris, Y.; Abdelaziz, A.M. Relationship between sperm progressive motility and DNA integrity in fertile and infertile men. Middle East Fertil. Soc. J. 2018, 23, 195-198. [CrossRef]

7. Hopps, C.V.; Mielnik, A.; Goldstein, M.; Palermo, G.D.; Rosenwaks, Z.; Schlegel, P.N. Detection of sperm in men with Y chromosome microdeletions of the AZFa, AZFb and AZFc regions. Hum. Reprod. 2003, 18, 1660-1665. [CrossRef]

8. Ozdemir, O.; Gül, E.; Kilicarslan, H.; Gokce, G.; Beyaztas, F.Y.; Ayan, S.; Sezgin, I. SRY and AZF gene variation in male infertility: A cytogenetic and molecular approach. Int. Urol. Nephrol. 2007, 39, 1183-1189. [CrossRef]

9. Gentiluomo, M.; Crifasi, L.; Luddi, A.; Locci, D.; Barale, R.; Piomboni, P.; Campa, D. Taste receptor polymorphisms and male infertility. Hum. Reprod. 2017, 32, 2324-2331. [CrossRef]

10. Aston, K.I.; Carrell, D.T. Genome-wide study of single-nucleotide polymorphisms associated with azoospermia and severe oligozoospermia. J. Androl. 2009, 30, 711-725. [CrossRef]

11. Hu, Z.; Xia, Y.; Guo, X.; Dai, J.; Li, H.; Hu, H.; Jiang, Y.; Lu, F.; Wu, Y.; Yang, X.; et al. A genome-wide association study in Chinese men identifies three risk loci for non-obstructive azoospermia. Nat. Genet. 2011, 44, 183-186. [CrossRef] [PubMed]

12. Okada, H.; Tajima, A.; Shichiri, K.; Tanaka, A.; Tanaka, K.; Inoue, I. Genome-Wide Expression of Azoospermia Testes Demonstrates a Specific Profile and Implicates ART3 in Genetic Susceptibility. PLoS Genet. 2008, 4, e26. [CrossRef] [PubMed]

13. Wu, J.; Hou, J.H.; Hsieh, T.-S. A new Drosophila gene wh (wuho) with WD40 repeats is essential for spermatogenesis and has maximal expression in hub cells. Dev. Biol. 2006, 296, 219-230. [CrossRef] [PubMed]

14. WHO. WHO Laboratory Manual for the Examination and Processing of Human Semen, 5th ed.; World Health Organization: Geneva, Switzerland, 2010.

15. Purcell, S.; Chang, C. Plink v1.9. Available online: https://www.cog-genomics.org/plink/ (accessed on 18 May 2021).

16. Chang, C.C.; Chow, C.C.; Tellier, L.C.A.M.; Vattikuti, S.; Purcell, S.M.; Lee, J.J. Second-generation PLINK: Rising to the challenge of larger and richer datasets. GigaScience 2015, 4, 7. [CrossRef]

17. Cheng, I.-C.; Chen, B.C.; Shuai, H.-H.; Chien, F.-C.; Chen, P.; Hsieh, T.-S. Wuho Is a New Member in Maintaining Genome Stability through its Interaction with Flap Endonuclease 1. PLoS Biol. 2016, 14, e1002349. [CrossRef]

18. Gao, X.; Starmer, J.; Martin, E.R. A multiple testing correction method for genetic association studies using correlated single nucleotide polymorphisms. Genet. Epidemiol. 2008, 32, 361-369. [CrossRef]

19. Pasqualotto, F.F.; Sobreiro, B.P.; Hallak, J.; Pasqualotto, E.B.; Lucon, A.M. Sperm concentration and normal sperm morphology decrease and follicle-stimulating hormone level increases with age. BJU Int. 2005, 96, 1087-1091. [CrossRef]

20. Zhong, H.-Z.; Lv, F.-T.; Deng, X.-L.; Hu, Y.; Xie, D.-N.; Lin, B.; Mo, Z.-N.; Lin, F.-Q. Evaluating $\gamma H 2 A X$ in spermatozoa from male infertility patients. Fertil. Steril. 2015, 104, 574-581. [CrossRef]

21. Riedl, S.J.; Salvesen, G.S. The apoptosome: Signalling platform of cell death. Nat. Rev. Mol. Cell Biol. 2007, 8, 405-413. [CrossRef]

22. Tahmasebi, S.; Khoutorsky, A.; Mathews, M.B.; Sonenberg, N. Translation deregulation in human disease. Nat. Rev. Mol. Cell Biol. 2018, 19, 791-807. [CrossRef]

23. Ikechebelu, J.; Adinma, B.; Orie, E.; Ikegwuonu, S. High prevalence of male infertility in southeastern Nigeria. J. Obstet. Gynaecol. 2003, 23, 657-659. [CrossRef] [PubMed]

24. Agarwal, A.; Mulgund, A.; Hamada, A.; Chyatte, M.R. A unique view on male infertility around the globe. Reprod. Biol. Endocrinol. 2015, 13, 37. [CrossRef]

25. Nagy, R.; Boutin, T.S.; Marten, J.; Huffman, J.E.; Kerr, S.M.; Campbell, A.; Evenden, L.; Gibson, J.; Amador, C.; Howard, D.M.; et al. Exploration of haplotype research consortium imputation for genome-wide association studies in 20,032 Generation Scotland participants. Genome Med. 2017, 9, 23. [CrossRef]

26. Rastegari, E.; Kajal, K.; Tan, B.-S.; Huang, F.; Chen, R.-H.; Hsieh, T.-S.; Hsu, H.-J. WD40 protein Wuho controls germline homeostasis via TRIM-NHL tumor suppressor Mei-p26 in Drosophila. Development 2020, 147, dev182063. [CrossRef] [PubMed]

27. Choi, Y.; Jeon, S.; Choi, M.; Lee, M.-H.; Park, M.; Lee, D.R.; Jun, K.-Y.; Kwon, Y.; Lee, O.-H.; Song, S.-H.; et al. Mutations in SOHLH1 gene associate with nonobstructive Azoospermia. Hum. Mutat. 2010, 31, 788-793. [CrossRef] [PubMed]

28. Miyamoto, T.; Hasuike, S.; Yogev, L.; Maduro, M.R.; Ishikawa, M.; Westphal, H.; Lamb, D.J. Azoospermia in patients heterozygous for a mutation in SYCP3. Lancet 2003, 362, 1714-1719. [CrossRef] 
29. Yatsenko, A.N.; Georgiadis, A.P.; Röpke, A.; Berman, A.J.; Jaffe, T.; Olszewska, M.; Westernströer, B.; Sanfilippo, J.; Kurpisz, M.; Rajkovic, A.; et al. X-Linked TEX11 Mutations, Meiotic Arrest, and Azoospermia in Infertile Men. N. Engl. J. Med. 2015, 372, 2097-2107. [CrossRef] [PubMed]

30. Shaheen, R.; Abdel-Salam, G.; Guy, M.P.; AlOmar, R.; Abdel-Hamid, M.S.; Afifi, H.H.; Ismail, S.; Emam, B.A.; Phizicky, E.M.; Alkuraya, F.S. Mutation in WDR4 impairs tRNA m7G46 methylation and causes a distinct form of microcephalic primordial dwarfism. Genome Biol. 2015, 16, 210. [CrossRef] [PubMed]

31. Dadoune, J.-P. Spermatozoal RNAs: What about their functions? Microsc. Res. Tech. 2009, 72, 536-551. [CrossRef]

32. Oscanoa, J.; Sivapalan, L.; Gadaleta, E.; Ullah, A.Z.D.; Lemoine, N.R.; Chelala, C. SNPnexus: A web server for functional annotation of human genome sequence variation (2020 update). Nucleic Acids Res. 2020, 48, W185-W192. [CrossRef]

33. Torres, A.G.; Batlle, E.; de Pouplana, L.R. Role of tRNA modifications in human diseases. Trends Mol. Med. 2014, $20,306-314$. [CrossRef] [PubMed]

34. Pereira, M.; Francisco, S.; Varanda, A.S.; Santos, M.; Santos, M.A.S.; Soares, A.R. Impact of tRNA Modifications and tRNAModifying Enzymes on Proteostasis and Human Disease. Int. J. Mol. Sci. 2018, 19, 3738. [CrossRef] [PubMed]

35. Lin, F.-J.; Shen, L.; Jang, C.-W.; Falnes, P.Ø.; Zhang, Y. Ikbkap/Elp1 Deficiency Causes Male Infertility by Disrupting Meiotic Progression. PLoS Genet. 2013, 9, e1003516. [CrossRef] [PubMed]

36. Giacone, F.; Cannarella, R.; Mongioì, L.M.; Alamo, A.; Condorelli, R.A.; Calogero, A.E.; La Vignera, S. Epigenetics of Male Fertility: Effects on Assisted Reproductive Techniques. World J. Men's Health 2019, 37, 148-156. [CrossRef] [PubMed]

37. Xu, J.; Zhang, A.; Zhang, Z.; Wang, P.; Qian, Y.; He, L.; Shi, H.; Xing, Q.; Du, J. DNA methylation levels of imprinted and nonimprinted genes DMRs associated with defective human spermatozoa. Andrologia 2016, 48, 1027-1035. [CrossRef] [PubMed] 